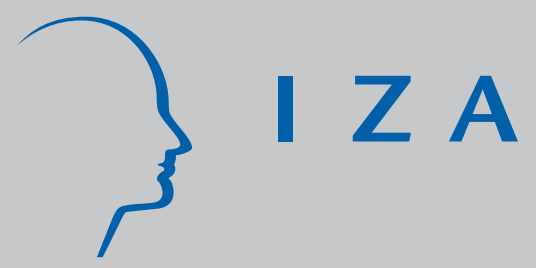

IZA DP No. 1040

Fiscal Policy and Educational Attainment in the United States - A Generational Accounting Perspective

Xavier Choj nicki

Frédéric Docquier

March 2004 


\title{
Fiscal Policy and Educational Attainment in the United States - A Generational Accounting Perspective
}

\author{
Xavier Chojnicki \\ MEDEE, University of Lille 1
}

Frédéric Docquier

CADRE, University of Lille 2, IWEPS and IZA Bonn

\section{Discussion Paper No. 1040 \\ March 2004}

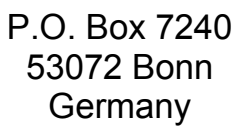

Phone: +49-228-3894-0

Fax: +49-228-3894-180

Email: iza@iza.org

\begin{abstract}
Any opinions expressed here are those of the author(s) and not those of the institute. Research disseminated by IZA may include views on policy, but the institute itself takes no institutional policy positions.
\end{abstract}

The Institute for the Study of Labor (IZA) in Bonn is a local and virtual international research center and a place of communication between science, politics and business. IZA is an independent nonprofit company supported by Deutsche Post World Net. The center is associated with the University of Bonn and offers a stimulating research environment through its research networks, research support, and visitors and doctoral programs. IZA engages in (i) original and internationally competitive research in all fields of labor economics, (ii) development of policy concepts, and (iii) dissemination of research results and concepts to the interested public.

IZA Discussion Papers often represent preliminary work and are circulated to encourage discussion. Citation of such a paper should account for its provisional character. A revised version may be available on the IZA website (www.iza.org) or directly from the author. 


\section{ABSTRACT \\ Fiscal Policy and Educational Attainment in the United States - A Generational Accounting Perspective*}

In this paper, we investigate the consequences of the rise in educational attainment on the US generational accounts. We build on the 1995 accounts of Gokhale et al. (1999) and disaggregate them per schooling level. We show that low skill newborns are characterized by a negative generational account $(-15.4 \%$ of their lifetime labor income) whilst medium and high skill newborns have positive accounts ( 26.8 and $32.3 \%$ of their lifetime labor income). Compared to Gokhale et al., our baseline forecast is more optimistic. Nevertheless, the rise in educational attainment is not strong enough to restore the generational balance. The current fiscal policy generates a long run deficit. Balancing the budget requires increasing taxes (by about $1.2 \%$ ) or reducing transfers (by about $2.7 \%$ ). These results are robust to growth and discounting assumptions, to the treatment of education spending. They are sensitive to assumptions about the schooling level of future generations.

JEL Classification: E62, H6, J24

Keywords: generational accounting, human capital, fiscal policy

Corresponding author:

Frédéric Docquier

CADRE

University of Lille 2

1 Place Déliot

50984 Lille

France

Email: f.docquier@skynet.be

\footnotetext{
* We thank the participants to the Conference of the European Economic and Financial Society (Bologna, May 2003) for helpful comments. Suggestions from Gilles Duranton, Joël Hellier, and Philip Oreopoulos were very appreciated. We are grateful to Alan Auerbach, Tim Miller and Philip Oreopoulos for transmitting their program and dataset. The usual disclaimers apply.
} 


\section{Introduction}

Since the seminal works of Auerbach, Gokhale and Kotlikoff $(1991,1994)$, and Kotlikoff (1992), generational accounting has usually been perceived as a meaningful way to evaluate the sustainability of fiscal policy. It builds on an original treatment of the government's intertemporal budget constraint: at any date, the present value of government purchases must be covered by the current net public wealth, the present value of net taxes which will be paid by living generations over the rest of their lifetime and the present value of net taxes which will be paid by future generations over their whole lifetime. The basic questions are: what burden must the government leave on future generations to remain solvent? Is the resulting fiscal treatment of future generations' members identical to that of the current newborns?

Economically, there is no reason for equalizing individual taxes and transfers. Most fiscal regimes involve high taxes for high income individuals and low taxes for less productive workers. The same rationale can be applied to intergenerational redistribution. If one generation is economically more productive than another (for example because its proportion of rich agents is higher), it seems justified to make it pay more taxes or receive less transfers. The generational accounting methodology partially takes account of differences in generational wealth by comparing generations in terms of fiscal pressure rather than on gross burden. Using balanced growth assumptions, the classical methodology defines the generationally balanced policy as a situation in which individual taxes and transfers increase at the same pace as labor 
productivity. However, existing generational accounting exercises rely on very simple assumptions about the changes in labor productivity and/or lifetime labor income across generations. Usually, these changes are related to a path of exogenous growth rates that have no explicit link with the skill composition of the generations. Hence, existing studies do not take account of an important source of heterogeneity within and between generations, i.e. the rise in educational attainment of successive cohorts.

The purpose of this paper is to revisit the US accounts of Gokhale, Page and Sturrock $(1999)^{1}$ by introducing skill heterogeneity in the generational accounting technique. ${ }^{2}$ GPS demonstrate that the US fiscal policy is unsustainable and generationally imbalanced. They evaluate the fiscal pressure imposed on a generation by its lifetime net tax rate, i.e. the ratio of the present value (at birth) of net taxes one generation has to pay to the government over its lifetime on the present value of its lifetime labor income. They show that the lifetime net tax rate of future generations amounts to $49.2 \%$, to be compared with $28.6 \%$ for the current newborns. Such a framework with a single representative agent within each generation fails to capture the evolution of skills. In this paper, we demonstrate that it is crucial to introduce skill heterogeneity for three main reasons:

\footnotetext{
${ }^{1}$ Henceforth GPS.

${ }^{2}$ It should be noted that heterogeneity has already been introduced in the generational accounting framework. Most existing works distinguish males and females. This can be important for illustrative purpose but has a smaller incidence on long-run evaluations since the sex composition of living and future cohorts is extremely stable over time. Other studies such as Auerbach and Oreopoulos (2000) on the US, Bonin and al. (1999) on Germany or Collado and al. (2001) on Spain distinguish between natives and immigrants so as to evaluate the fiscal effect of immigration policies. This is obviously pertinent in countries where migrants represent a large share of the population and/or where selective immigration policies are explicit.
} 
- firstly, it concerns the US population as a whole;

- secondly, the age-profile of taxes and transfers is highly dependent on educational attainment. We distinguish three large categories of education: less than high school $(<\mathrm{HS})$, high school $(\mathrm{HS})$ and more than high school $(>\mathrm{HS})$. According to our estimations, the average lifetime income of a low skill individual amounts to $\$ 81,373$ to be compared to $\$ 174,293$ for a medium skill worker and $\$ 311,540$ for a high skill worker. On the contrary, the present value of public benefits received by an agent over her whole lifetime amounts to $\$ 58,063$ for the low skilled, $\$ 30,974$ for the medium skilled and $\$ 21,373$ for the high skilled;

- finally, the skill composition of the population drastically changes over time and is likely to evolve in future years. In 1995, numbers taken from Lee and Miller (1997) reveal that 64 percent of the population aged 80 had a diploma lower than high school, against 24 percent for those graduated from high school and 12 percent for those higher than high school. For the cohort aged 55, these numbers were respectively 21 percent, 38 percent and 41 percent. For the cohort aged 30 in 1995, we have 13 percent, 35 percent and 52 percent. Obviously, skill heterogeneity is very strong among living generations. According to the forecasts of Lee and Miller (1997), these proportions are likely to change in the future, respectively converging towards 10.9 percent, 28.9 percent and 60.2 percent for future cohorts of adults with completed schooling. Such a forecast can be seen as a medium variant, lying between the "low projection" and the 
"high projection" of Cheeseman Day and Bauman (2000).

The rise in education attainment can be explained by several factors (public education expenditures, rise in the skill premium...). For the next decades, the increase in human capital per worker seems rather ineluctable as new educated cohorts will progressively replace older less educated ones. These changes are likely to generate fiscal gains for the government. We argue that education is a key parameter for evaluating the long-run sustainability of the current policy. By disregarding such changes, the generational accounting technique induces two biases:

- extrapolating the living generation's accounts on the basis of the current net tax profile and common growth assumptions for taxes and benefits, the technique is likely to lead to an underestimation of the net payments by living cohorts. It makes little sense to assume that average net taxes of the generation aged 20 in 1995 can be projected on the basis on average net taxes paid by the current older generations. Taking account of specific profiles per schooling level and changes in the skill composition of living cohorts allows to determine more accurate path of net taxes for future years. This improves the evaluation of the total burden left on future generations;

- evaluating the lifetime net tax rate of future generations must account for the real lifetime labor income of these cohorts. These amounts obviously depend on general assumption about total factor productivity but also on assumptions about the skill composition of future generations. By disregarding the skill 
structure of future generations, the accounting technique is likely to underestimate the lifetime labor income of these cohorts.

In the rest of this paper, we show that the rise in educational attainment strongly modifies the conclusion of GPS. To make comparisons relevant, our analysis is also based on the 1995 fiscal year and our adjustment calculations rely on the counterfactual hypothesis that all changes begin in 1995. Generally speaking, our paper provides a sensitivity analysis to GPS benchmark assumptions. Our conclusions are more optimistic and raise numerous issues about educational policies and social mobility (how to increase the incentives to educate? Would the cost of increasing the average schooling level exceed the fiscal gains?), about the political sustainability of current taxes and transfers (if the government deficit decreases, will there be a fiscal pressure to reduce taxes or to increase transfers) and about the structure of the labor market (can these fiscal gains resist to the increasing supply of skills?). Nevertheless, the only purpose of our contribution is to compute the impact of educational changes on the government budget constraint all other things being constant, i.e. taking the economic environment as given. Consequently, our results must exclusively be appreciated in terms of fiscal sustainability.

Section 2 discusses data issues and the calibration of net tax profiles per age and education level. It is shown that educational attainment affects both taxes and benefits. However, differences in tax profiles are stronger. Generational accounts per skill are then computed in section 3. As in GPS, our basic assumptions about 
the growth rates of per capita taxes and benefits build on the official projections of the Congressional Budget Office $(\mathrm{CBO}){ }^{3}$ The term "fiscal policy" then reflects both the current age profile of net taxes (per age and educational level) and official growth rates for per capita amounts. Our results indicate that low skill newborns are characterized by a negative generational account (-15.4 percent of their lifetime labor income). Lifetime net tax rates for medium and high skill newborns are positive and amount to 26.8 percent and 32.3 percent.

Taking account of the rise in educational attainment has a strong impact on the results. Compared to GPS, it is shown that the total burden left on future generations is reduced by about 30.7 percent in our baseline scenario. Consequently, our results are more optimistic. Nevertheless, we show that the drastic rise in educational attainment do not restore the fiscal sustainability. Balancing the long-run deficit requires increasing taxes (by about 1.2 percent) or reducing transfers (by about 2.7 percent). This contrasts with the study of GPS which reveals that restoring the generational balance in 1995 requires cutting all transfers by 17.5 percent or increasing all taxes by 8.2 percent. Section 4 provides a similar exercise by considering public education expenditures as transfers rather than a part of government purchases. Similar results are obtained but the government deficit becomes slightly higher than in the baseline scenario. Restoring the balance allows to increase taxes by 1.4 percent or to cut transfers by 2.4 percent. A sensitivity analysis is presented in section 5 . Section 6

\footnotetext{
${ }^{3}$ See CBO (1997a, 1997b).
} 
concludes. An appendix provides our mathematical tools for generational accounting with heterogenous skills and an alternative simulation closer to the CBO aggregate projections. However, we show that the latter scenario is rather inconsistent with the assumption about labor productivity growth. We conclude that changes in educational attainment is a key parameter for analyzing the sustainability of the fiscal policy.

\section{Data issues}

Estimating the age profiles of taxes and benefits for a reference year is the building block for any longitudinal calculation. In this paper, we use GPS estimates of the contemporary profiles for men and women in 1995. We aggregate men and women profiles using sex composition data per age. These profiles concern six types of tax (Labor Income taxes, FICA taxes, Excise taxes, Capital Income taxes, Seignorage taxes and Property taxes), seven types of benefit (OASDI, Medicare, Medicaid, Unemployment Insurance, General Welfare, AFDC and Food Stamps) and three items of government purchases (Education expenditures, Federal government purchases and State government purchases). These profiles are scaled so as to match aggregated observations (i.e. the observed shares in GDP). The continuous lines (in black) on fig. 1.1 and fig. 1.2 represent the total taxes and total benefits paid or received (excluding education spending) by the representative agent of each living cohort in 1995. The continuous line (in black) on fig. 1.3 gives the difference between taxes paid and 
benefits received. It appears that net taxes are positive for individuals aged 15 to 70 (net contributors) and negative for individuals above age 70 (net beneficiaries).

These representative profiles represent the weighted average of net taxes paid by all the US residents in 1995. These age-specific amounts are thus depending on the average characteristics of living cohorts, i.e. on their sex composition, their average skill levels, their nativity... In this paper, we disaggregate these amounts per educational level. This requires disaggregating each tax or benefit item of the GPS dataset. Three educational levels are distinguished: individual with a less than high school diploma $(<\mathrm{HS})$, those with a high school diploma (HS) and those with a more than high school diploma ( $>\mathrm{HS})$. 

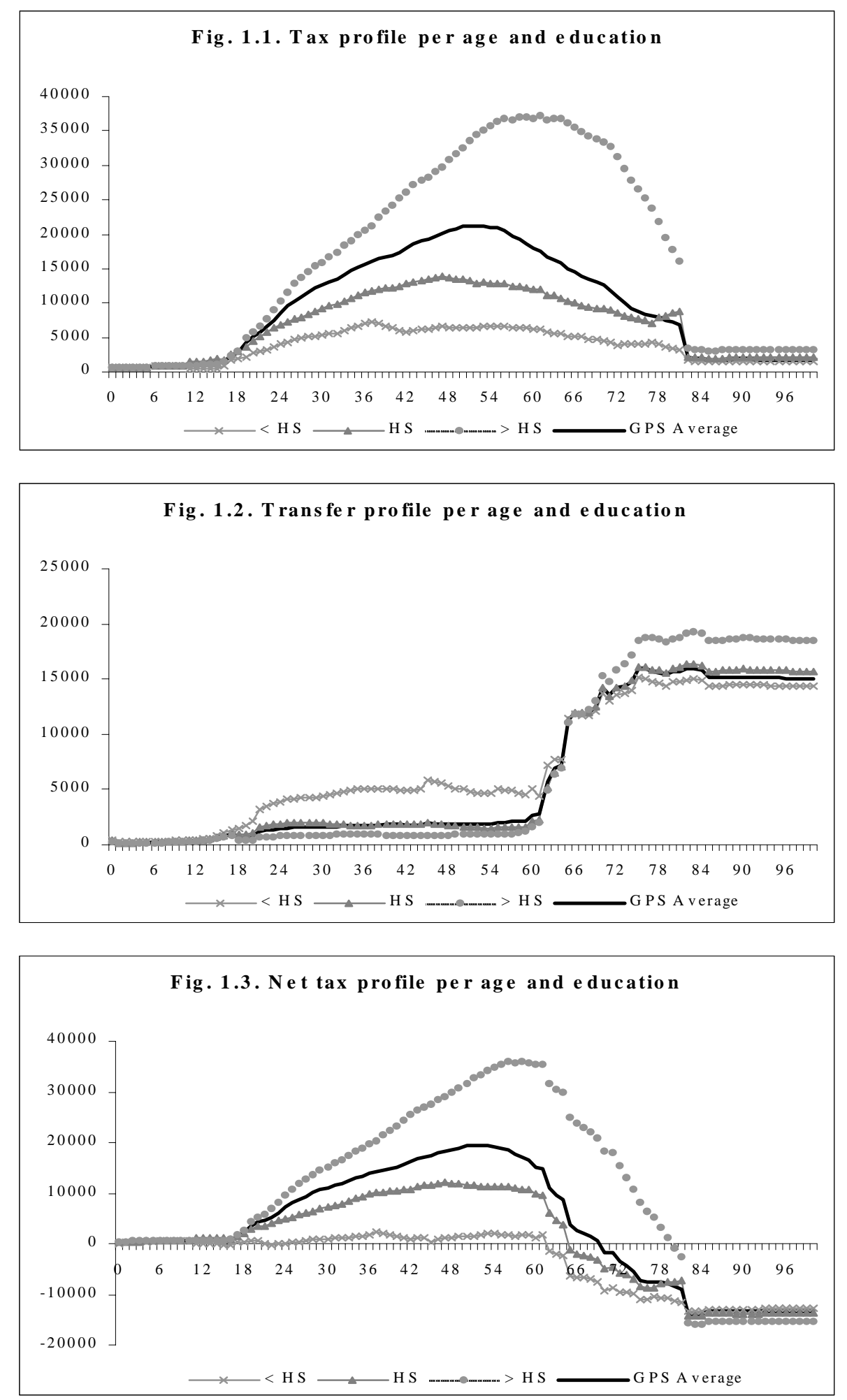

Note: Present values in 1995 dollars 
Two statistical sources are used :

- regarding labor income taxes, capital income taxes and OASDI benefits, we use data extracted from the PSID (Panel Study on Income Dynamics ${ }^{4}$ ) of the US population aged 20 and more in 1993. For these individuals, the education level is reported. After elimination of illogical and non responses, we compute the representative profiles for these items on the basis of 17,943 observations. For those aged less than 20, we consider that the profiles are identical. PSID data are also used to compute the lifetime labor income per schooling level;

- regarding other items of taxes and benefits (including public education expenditures), we use the profiles estimated by Lee and Miller (1997) per educational level, per cohort and, for immigrants only, by date of entry. These profiles are based on 1994 and 1995 data from the CPS (Current Population Surveys). For individuals aged 20 and more, the education level is reported. For children (aged 0 to 19), education is forecast on the basis of parent's level and ethnicity. We do not distinguish between immigrants and natives.

All these disaggregated profiles are then calibrated so as to be consistent with the GPS averages. We use data on the skill composition of the US living cohorts in 1995 from Lee and Miller (1997). For the population aged 20 and more, these data correspond to the education levels measured in the US General Social Survey (GSS).

\footnotetext{
${ }^{4}$ These data are available from the website: http://www.isr.umich.edu/src/psid.
} 
For the population aged 0 to 19 (those reaching age 20 between 1996 and 2015), Lee and Miller (1997) forecast educational attainment on the basis of parents' level of education and ethnicity. Then, we consider that the skill structure of future cohorts (aged 20 after 2015) is stationary. Compared to existing studies, our scenario can be seen as a medium variant. It lies between the "low projection" and the "high projection" provided in Cheeseman Day and Bauman (2000).

The first column of table 1 gives the cohort shares per educational level in 1995. It appears that 52.0 percent of the population aged 30 has a diploma higher than high school, against 35.0 percent for those graduated from high school and 13.0 percent for those lower than high school. At 60 years old, these numbers were respectively 36.6 percent, 36.9 percent and 26.5 percent. For the newborns, they should be 60.2 percent, 28.9 percent and 10.9 percent.

The rest of table 1 thus provides age profiles per educational level fully consistent with the GPS estimates. We only report the main categories of taxes and transfers. Fig. 1.1 to 1.3 give the disaggregation per schooling level of total taxes, total benefits and net taxes for each living age group. The impact of educational attainment is mainly perceptible for taxes: at 60 years old, the taxes paid by a high skill individual are six times as large as the amount paid by a low skill individual. However, smaller differences are also appearing in benefit profiles. In terms of net taxes, low skill agents are obviously the main beneficiaries of the fiscal policy whilst medium and high skill agents are the contributors. At age 60, the ratio of net taxes between a high skilled 
and a medium skilled is about 3.5. Hence, it makes no doubt that changes in the educational structure strongly affect the sustainability of the current fiscal policy.

Table 1. Age profiles per educational level - 1995

\begin{tabular}{|c|c|c|c|c|c|c|c|c|}
\hline & $\begin{array}{l}\text { Cohort } \\
\text { Share }\end{array}$ & $\begin{array}{c}\text { Labor } \\
\text { Income Tax }\end{array}$ & $\begin{array}{c}\text { Capital } \\
\text { Income Tax }\end{array}$ & FICA Tax & $\begin{array}{l}\text { Other } \\
\text { Taxes }\end{array}$ & OASDI & $\begin{array}{c}\text { Medicare } \\
\text { \& Medicaid }\end{array}$ & $\begin{array}{c}\text { Other } \\
\text { benefits }\end{array}$ \\
\hline \multicolumn{9}{|c|}{ Less than High School } \\
\hline 0 & $10.9 \%$ & 0 & 0 & 0 & 549 & 7 & 446 & 0 \\
\hline 20 & $16.1 \%$ & 336 & -5 & 880 & 1545 & 13 & 669 & 1450 \\
\hline 30 & $13.0 \%$ & 1187 & 158 & 2086 & 1935 & 86 & 1863 & 2462 \\
\hline 40 & $11.2 \%$ & 1474 & 339 & 2185 & 2334 & 345 & 2406 & 2250 \\
\hline 50 & $16.3 \%$ & 1418 & 273 & 2288 & 2403 & 446 & 3109 & 1434 \\
\hline 60 & $26.5 \%$ & 995 & 490 & 1508 & 3172 & 1133 & 2995 & 863 \\
\hline 70 & $33.1 \%$ & 153 & 692 & 211 & 3363 & 7320 & 5473 & 864 \\
\hline 100 & $64.0 \%$ & 28 & 0 & 30 & 1472 & 7090 & 6787 & 450 \\
\hline \multicolumn{9}{|c|}{ High School } \\
\hline 0 & $28.9 \%$ & 0 & 0 & 0 & 549 & 7 & 342 & 0 \\
\hline 20 & $32.3 \%$ & 1080 & 37 & 1365 & 2023 & 22 & 340 & 675 \\
\hline 30 & $35.0 \%$ & 2655 & 262 & 3432 & 2749 & 67 & 786 & 1086 \\
\hline 40 & $32.0 \%$ & 3068 & 990 & 3761 & 4404 & 210 & 840 & 860 \\
\hline 50 & $35.2 \%$ & 2963 & 1167 & 4036 & 5210 & 315 & 874 & 457 \\
\hline 60 & $36.9 \%$ & 2015 & 1496 & 2472 & 5985 & 812 & 978 & 282 \\
\hline 70 & $36.5 \%$ & 269 & 1851 & 301 & 6712 & 8870 & 5175 & 155 \\
\hline 100 & $24.0 \%$ & 79 & 0 & 52 & 1918 & 8897 & 6666 & 140 \\
\hline \multicolumn{9}{|c|}{ More than High School } \\
\hline 0 & $60.2 \%$ & 0 & 0 & 0 & 549 & 7 & 247 & 0 \\
\hline 20 & $51.6 \%$ & 1245 & 336 & 1332 & 2846 & 12 & 150 & 272 \\
\hline 30 & $52.0 \%$ & 4439 & 1016 & 5001 & 5443 & 83 & 317 & 444 \\
\hline 40 & $56.8 \%$ & 5356 & 2839 & 5955 & 9936 & 135 & 337 & 385 \\
\hline 50 & $48.6 \%$ & 6019 & 4999 & 6184 & 15246 & 246 & 445 & 257 \\
\hline 60 & $36.6 \%$ & 4211 & 7506 & 4434 & 20711 & 784 & 575 & 180 \\
\hline 70 & $30.4 \%$ & 894 & 8690 & 952 & 22878 & 10012 & 5072 & 183 \\
\hline 100 & $12.0 \%$ & 59 & 0 & 134 & 2973 & 11769 & 6593 & 116 \\
\hline \multicolumn{9}{|c|}{ Weighted average (a) } \\
\hline 0 & - & 0 & 0 & 0 & 549 & 7 & 296 & 0 \\
\hline 20 & - & 1045 & 184 & 1270 & 2371 & 15 & 295 & 591 \\
\hline 30 & - & 3392 & 640 & 4073 & 4044 & 78 & 682 & 931 \\
\hline 40 & - & 4191 & 1969 & 4832 & 7318 & 183 & 729 & 746 \\
\hline 50 & - & 4196 & 2882 & 4795 & 9627 & 303 & 1029 & 518 \\
\hline 60 & - & 2549 & 3430 & 2935 & 10631 & 887 & 1365 & 399 \\
\hline 70 & - & 421 & 3547 & 469 & 10518 & 8704 & 5242 & 398 \\
\hline 100 & - & 44 & 0 & 48 & 1759 & 8085 & 6735 & 336 \\
\hline
\end{tabular}

Note: $\quad$ (a) Weighted averages corresponding to GPS profiles

Source: $\quad$ GPS; PSID; Lee and Miller (1997); Authors' calculations 


\section{Revisiting 1995 generational accounts}

Let us now introduce the disaggregated net tax profiles in the generational accounting framework. The starting point of generational accounting is the government's intertemporal budget constraint. At the base year 1995, the sum of the public net wealth and the present value of prospective aggregate net payments by living and future generations must equalize the present value of prospective public purchases. The public net wealth is the only observable item of this constraint : it amounts to $-\$ 2.1$ trillion in 1995. Regarding generational accounts of living and future generations, we follow GPS and proceed as following.

Using assumptions about the time path of government purchases and individual amounts of tax and transfer for living generations enables to derive the present value of government purchases and payments by living generations. It is also possible to compute the hypothetical generational accounts of future cohorts under the same fiscal policy than for living cohorts. Combining these amounts into the government intertemporal budget constraint, we compute the fiscal adjustment required to balance the budget. This adjustment affects taxes and/or transfers from 1995 onwards. Hence, it impacts on the situation of both living and future generations. Depending on the type of adjustment we opt for, we compute the "adjusted" generational accounts of living and future generations that are budgetary sustainable. Finally, these "adjusted" payments made by the newborns and individuals not yet born can be compared on a lifetime basis. The technical appendix 8.1 describes our methodology. 
The present value of government purchases (PVG). The PVG is the discounted sum of government purchases (State and Federal purchases, including educational expenditures) from 1995 under the assumed fiscal policy. Our baseline scenario builds on GPS study. Through 2070, we then use the path of government purchases simulated by the Congressional Budget Office. Beyond 2070, government purchases are supposed to grow by 1.2 percent per year. The baseline discount rate is 6 percent.

The present value of payments by living generations (PVL). The PVL sums up generational accounts of all the members of living generations. By generational account, we mean the present value of net taxes that a member of a group will pay over the rest of her life under the assumed fiscal policy. Evaluating the accounts of living generations then requires a long-run prospective calculations relying on some crucial assumptions about the demographic size of each living generation, its educational structure, the evolution of per capita taxes and benefits and the economic environment. Here is a description of the main assumptions:

- our baseline scenario relies on the intermediate population projection of the Social Security Administration (SSA), extended by GPS projections beyond 2070 (assuming that fertility, mortality and net immigration rates remain at their 2070 level. This scenario implies a sharp deterioration of the old-age dependency ratio (i.e. the ratio of people aged $65+$ to people aged $15-64$ ). The ratio amounts to $19 \%$ in 2000 and is expected to reach more than $33 \%$ in 2050 and about $40 \%$ in 2100 ; 
- the growth rates of per capita taxes and benefits are those used in GPS study, themselves building on the reference projection of the Congressional Budget Office through 2070. A growth path is calculated for each item of tax and benefit. We equivalently apply these growth rates to per capita amounts paid (or received) by the members of each educational category. For a given path of growth rates, our fiscal projections are affected by the changes in educational structure and in demographic size (while GPS/CBO aggregates are only affected by the demography). An alternative scenario would be to calibrate the growth rates so as to match the $\mathrm{CBO}$ aggregate projections per item. Nevertheless, appendix 8.2 shows that our baseline scenario is more consistent with the assumption about labor productivity growth than aggregate budgetary forecasts ${ }^{5}$. Consequently, our projections do not correspond to those of the Congressional Budget Office;

- the net tax profiles are assumed to be stable over time. It could be argued that the rise in educational attainment will impact on the return to skill and reduce the gap between skilled and unskilled workers even if it did not happen in the past decades (between 1970 and 2000, the return to skills has increased despite a remarkable rise in educational attainment). It could also be argued that the

\footnotetext{
${ }^{5}$ The CBO projection does not take account of the rise in educational level of the population. In appendix 8.2, we compare our baseline scenario (based on CBO growth rates for per capita taxes and transfers) with an alternative scenario based on CBO aggregated projections. This requires calibrating the alternative growth rates of per capita taxes and benefits so as to match GPS/CBO aggregate amounts. Our calculations show that the resulting growth rates are hardly consistent with the 1.2 percent growth rate of labor productivity.
} 
rise in school attendance will change the average cost of education per student. However, endogenizing the tax profiles is beyond the scope of our accounting study;

- the educational attainment of living generations in 1995 is depicted in table 1. For each living generation, the educational structure is assumed to be constant over time. Given the absence of life table per educational attainment, we disregard the effect of heterogeneity in mortality (life expectancy is usually higher for the high skilled) as well as the timing of immigration flows (for young generations, future immigration flows are likely to reduce the share of skilled workers over time);

- as for the PVG, the discount rate is set to 6 percent. The growth rate of individual taxes and transfers beyond 2070 is set to 1.2 percent.

Generational accounts of living generations are given in table 2. It clearly appears that the generational account of a low skill newborn is negative. On their whole lifetime, unskilled agents are expected to receive more transfers than paying taxes to the government. On the opposite, generational accounts of medium and high skill individuals are positive. More particularly, the average generational account of a high skill newborn is twice as large as the account of a medium skill newborn. It is also worth noticing that generational accounts of low skill agents are always negative while it is only the case after age 53 for the medium skilled and after age 64 for the high skilled. To compare everyone on the same basis, GPS suggest to calculate the lifetime 
net tax rates, i.e. the ratio of generational account on the present value of lifetime labor income. This exercise can be done for each educational group. As it will appear in table 3 , the lifetime net tax rates of newborns amount to -15.4 percent for the low skilled, 26.8 percent for the medium skilled and 32.3 percent for the high skilled. The average lifetime net tax rate then amounts to $32.1 \%$ (against $28.6 \%$ in GPS study).

Given the changes in the skill composition of these living cohorts, our average generational accounts per cohort are not identical to GPS amounts. This appears on the bottom part of table 1 and on fig. 2. The differences are small for old-age cohorts rather large for young cohorts. Extrapolating the future taxes and transfers of newborns on the sole basis of the contemporaneous profile, the classical method underevaluates the newborns' average account by 10.7 percent. 
Table 2. Generational accounts of living generations Baseline scenario (a)

\begin{tabular}{|c|c|c|c|c|}
\hline & $\begin{array}{l}\text { Present value of } \\
\text { taxes }\end{array}$ & $\begin{array}{c}\text { Present value of } \\
\text { benefits }\end{array}$ & $\begin{array}{c}\text { Generational } \\
\text { accounts }\end{array}$ & GPS estimates \\
\hline & \multicolumn{3}{|c|}{ Less than High School } & \\
\hline 0 & 45552 & -58063 & -12511 & - \\
\hline 20 & 91345 & -114177 & -22832 & - \\
\hline 30 & 93963 & -120576 & -26612 & - \\
\hline 40 & 83769 & -123509 & -39740 & - \\
\hline 50 & 66764 & -127465 & -60701 & - \\
\hline 60 & 41724 & -143701 & -101977 & - \\
\hline 70 & 23742 & -140866 & -117124 & - \\
\hline \multirow[t]{2}{*}{100} & 1529 & -14328 & -12798 & - \\
\hline & \multicolumn{3}{|c|}{ High School } & \\
\hline 0 & 77682 & -30974 & 46708 & - \\
\hline 20 & 160019 & -58543 & 101476 & - \\
\hline 30 & 165160 & -63977 & 101183 & - \\
\hline 40 & 151898 & -76054 & 75844 & - \\
\hline 50 & 118288 & -98194 & 20094 & - \\
\hline 60 & 73049 & -139618 & -66568 & - \\
\hline 70 & 41400 & -149275 & -107875 & - \\
\hline \multirow[t]{2}{*}{100} & 2049 & -15704 & -13655 & - \\
\hline & \multicolumn{3}{|c|}{ More than High School } & \\
\hline 0 & 121860 & -21373 & 100487 & - \\
\hline 20 & 274928 & -40601 & 234327 & - \\
\hline 30 & 309355 & -50327 & 259028 & - \\
\hline 40 & 311983 & -67363 & 244620 & - \\
\hline 50 & 276591 & -98489 & 178102 & - \\
\hline 60 & 194531 & -149011 & 45520 & - \\
\hline 70 & 114091 & -170570 & -56479 & - \\
\hline \multirow[t]{2}{*}{100} & 3167 & -18478 & -15311 & - \\
\hline & \multicolumn{3}{|c|}{ Weighted average } & \\
\hline 0 & 100790 & -28140 & 72650 & 64910 \\
\hline 20 & 208241 & -58235 & 150006 & 149355 \\
\hline 30 & 230878 & -64238 & 166640 & 159492 \\
\hline 40 & 235294 & -76415 & 158880 & 135353 \\
\hline 50 & 186775 & -103095 & 83680 & 65347 \\
\hline 60 & 109224 & -144138 & -34913 & -39160 \\
\hline 70 & 57654 & -152966 & -95312 & -95738 \\
\hline 100 & 1851 & -15156 & -13305 & -13305 \\
\hline
\end{tabular}

Note:

(a) Present value in 1995 dollars

Source: Authors' calculations 


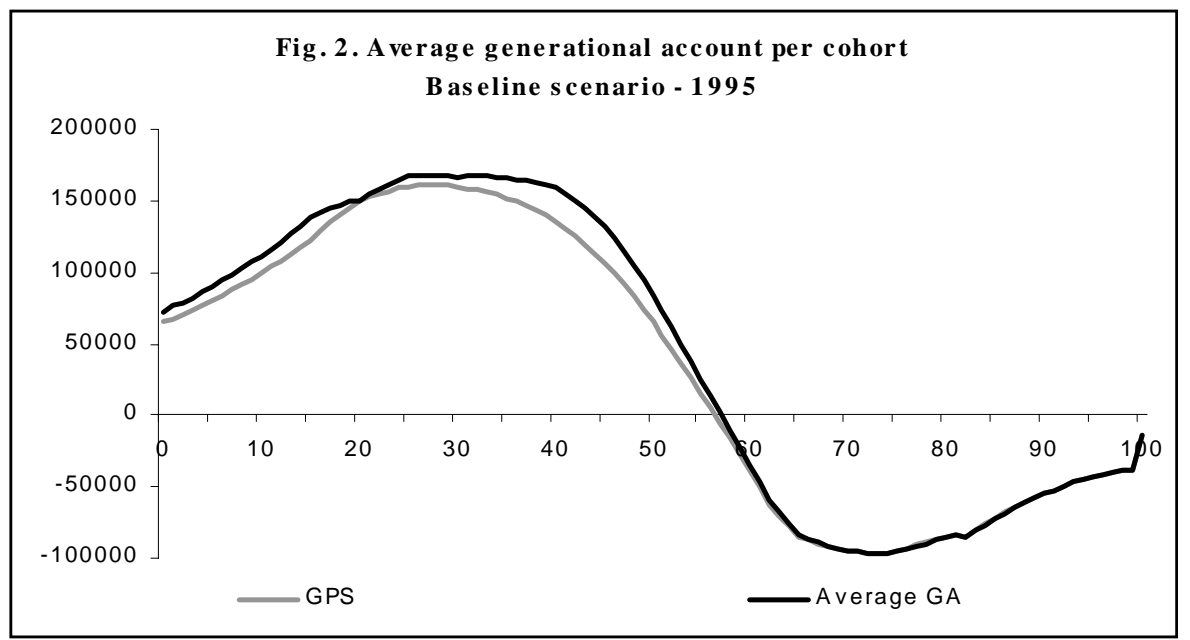

Burden left on future generations. The total burden left on future generations is directly obtained as the residual of the government's budget constraint. It amounts to $\$ 6,509$ billions instead of $\$ 9,398$ in the GPS methodology. This is due to the fact that the usual methodology underevaluates the total payments made by living generations.

Balancing generational accounts. Examining the sustainability of the fiscal policy requires computing the present value of payments by future generations under the current policy (based on the assumptions of Congressional Budget Office about the growth rate of per capita taxes and transfers). For this purpose, we use our forecasts about the educational structure of future generations. Despite the remarkable rise in educational attainment, maintaining the current policy for future generations generates a present value of payments lower than the total burden left by living generations. In words, the current fiscal policy is still unsustainable.

Restoring the balance thus requires cutting transfers or increasing taxes. In the 
classical method of generational accounting, such an adjustment is implemented by multiplying net taxes of future generations by a constant adjustment factor. In our case with heterogenous agents, such a rule would give rise to inconsistent results since generational accounts are of opposite signs. For example, multiplying generational accounts by 1.1 would induce more fiscal effort for individuals with a positive account at birth, but a lower effort for those with a negative account. Moreover, it seems quite unrealistic to adjust the accounts of future generations only. As argued by Haveman (1994), both living and future generations are likely to be concerned by fiscal changes. For these reasons, we use an adjustment method which concerns all the members of all the generations. In a first step, we compute the present value of payments by future generations under the current fiscal policy. Comparing this amount to the residual burden given by the budget constraint, we obtain the gap to be financed by (in case of deficit) or to be allocated to (in case of surplus) all living and future generations. In a second step, we compute the proportional adjustment in all taxes (or in all transfers) required to balance the budget. Finally, given the "adjusted" fiscal policy, we derive the new generational accounts and lifetime net tax rate. ${ }^{6}$ Our adjustment calculations rely on the counterfactual assumption that all changes begin in 1995.

Table 3 summarizes our results. Restoring the balance through tax adjustment induces a rise in all taxes by 1.16 percent. The lifetime net tax rates then become

\footnotetext{
${ }^{6}$ Our strategy slightly differs from GPS who compute the changes in taxes and/or benefits so as to equalize the lifetime net tax rates of current and future generations.
} 
-14.7 percent, 27.3 percent and 32.7 percent. Restoring the balance through transfer adjustment induces a cut in all transfers by 2.68 percent. The lifetime net tax rates then become -13.5 percent, 27.3 percent and 32.4 percent. These results contrast with GPS who predict that generational balance requires increasing all taxes by 8.2 percent or reducing all benefits by 17.5 percent. This demonstrates the huge potential impact of the rise in educational attainment in evaluating the long-run sustainability of fiscal policies.

Table 3. Generational imbalance and lifetime net tax rates

Baseline scenario (a)

\begin{tabular}{c|cccc}
\hline & $\begin{array}{c}\text { Present value of } \\
\text { taxes }\end{array}$ & $\begin{array}{c}\text { Present value of } \\
\text { benefits }\end{array}$ & $\begin{array}{c}\text { Generational } \\
\text { accounts }\end{array}$ & $\begin{array}{c}\text { Lifetime Net Tax } \\
\text { Rate (b) }\end{array}$ \\
\hline & Newborns' generational account and lifetime tax rate without policy adjustment \\
\hline$<$ HS & 45552 & -58063 & -12511 & $-15.4 \%$ \\
HS & 77682 & -30974 & 46708 & $26.8 \%$ \\
$>$ HS & 121860 & -21373 & 100487 & $32.3 \%$ \\
\hline & Restoring the balance through tax adjustment $(+1.16 \%)$ & \\
\hline$<$ HS & 46080 & -58063 & -11983 & $-14.7 \%$ \\
HS & 78582 & -30974 & 47608 & $27.3 \%$ \\
$>$ HS & 123272 & -21373 & 101899 & $32.7 \%$ \\
\hline & Restoring the balance through transfer adjustment $(-2.68 \%)$ & $-13.5 \%$ \\
\hline <HS & 45552 & -56504 & -10952 & $27.3 \%$ \\
HS & 77682 & -30142 & 47540 & $32.4 \%$ \\
$>$ HS & 121860 & -20800 & 101061 & \\
\hline
\end{tabular}

Note: $\quad$ (a) Present value in 1995 dollars

(b) Lifetime net tax rate $=$ generational account $/$ discounted lifetime labor income

Source: Authors' calculations 


\section{Distributing education expenditures per age and schooling level}

In the line of GPS, let us now consider another scenario in which public education expenditures (about one fifth of government purchases) are treated as individual transfers. In our baseline scenario, education spending are evolving at the same pace as the rest of government purchases such as defense or administration. In this new scenario (labelled as "Education Benefit"), they evolve with the demography (the number of individual in age of schooling), the educational composition of successive cohorts (determining the length and the cost of schooling) and with common growth assumption taken from GPS study. This scenario is then extremely important for our study. Table 4 gives the generational accounts of living generations. 
Table 4. Generational accounts of living generations Education benefit scenario (a)

\begin{tabular}{|c|c|c|c|c|}
\hline & $\begin{array}{c}\text { Present value of } \\
\text { taxes }\end{array}$ & $\begin{array}{l}\text { Present value of } \\
\text { benefits }\end{array}$ & $\begin{array}{l}\text { Generational } \\
\text { accounts }\end{array}$ & GPS estimates \\
\hline & \multicolumn{3}{|c|}{ Less than High School } & \\
\hline 0 & 45552 & -101081 & -55529 & - \\
\hline 20 & 91345 & -117060 & -25714 & - \\
\hline 30 & 93963 & -122286 & -28322 & - \\
\hline 40 & 83769 & -124261 & -40492 & - \\
\hline 50 & 66764 & -127653 & -60888 & - \\
\hline 60 & 41724 & -143799 & -102075 & - \\
\hline 70 & 23742 & -140893 & -117151 & - \\
\hline \multirow[t]{2}{*}{100} & 1529 & -14330 & -12801 & - \\
\hline & \multicolumn{3}{|c|}{ High School } & \\
\hline 0 & 77682 & -73246 & 4436 & - \\
\hline 20 & 160019 & -60986 & 99033 & - \\
\hline 30 & 165160 & -65687 & 99473 & - \\
\hline 40 & 151898 & -76805 & 75092 & - \\
\hline 50 & 118288 & -98381 & 19906 & - \\
\hline 60 & 73049 & -139715 & -66666 & - \\
\hline 70 & 41400 & -149303 & -107902 & - \\
\hline \multirow[t]{2}{*}{100} & 2049 & -15707 & -13658 & - \\
\hline & \multicolumn{3}{|c|}{ More than High School } & \\
\hline 0 & 121860 & -80451 & 41409 & - \\
\hline 20 & 274928 & -56460 & 218468 & - \\
\hline 30 & 309355 & -52037 & 257318 & - \\
\hline 40 & 311983 & -68115 & 243868 & - \\
\hline 50 & 276591 & -98676 & 177915 & - \\
\hline 60 & 194531 & -149108 & 45423 & - \\
\hline 70 & 114091 & -170598 & -56507 & - \\
\hline \multirow[t]{2}{*}{100} & 3167 & -18480 & -15313 & - \\
\hline & \multicolumn{3}{|c|}{ Weighted average } & \\
\hline 0 & 100790 & -80613 & 20177 & 13153 \\
\hline 20 & 208241 & -67668 & 140573 & 139868 \\
\hline 30 & 230878 & -65948 & 164930 & 157782 \\
\hline 40 & 235294 & -77166 & 158128 & 134602 \\
\hline 50 & 186775 & -103282 & 83493 & 65159 \\
\hline 60 & 109224 & -144235 & -35011 & -39257 \\
\hline 70 & 57654 & -152993 & -95339 & -95765 \\
\hline 100 & 1851 & -15159 & -13308 & -13308 \\
\hline
\end{tabular}

Note:

(a) Present value in 1995 dollars

Source: Authors' calculations

Treating education spending as benefits obviously reduces newborns' accounts for each schooling level. The differences with the baseline scenario amounts to $\$ 43,000$ for the low skilled, $\$ 42,300$ for the medium skilled and $\$ 59,000$ for the high skilled. These 
numbers measure the cost of education (in present value at birth). The changes are important for individual aged 25 and less. They are minor for older generations for which mandatory education belongs to the past. As it will appear on table 5 , lifetime net tax rates of newborns become -68.2 percent, 2.5 percent and 13.3 percent.

Once again, our average generational accounts per cohort are not identical to GPS amounts. This clearly appears on fig. 3. The differences are small for old-age cohorts but they are larger for young cohorts. Extrapolating the future taxes and transfers of newborns on the basis of the contemporary profile, the classical method underevaluates the newborns' average account by about 35 percent.

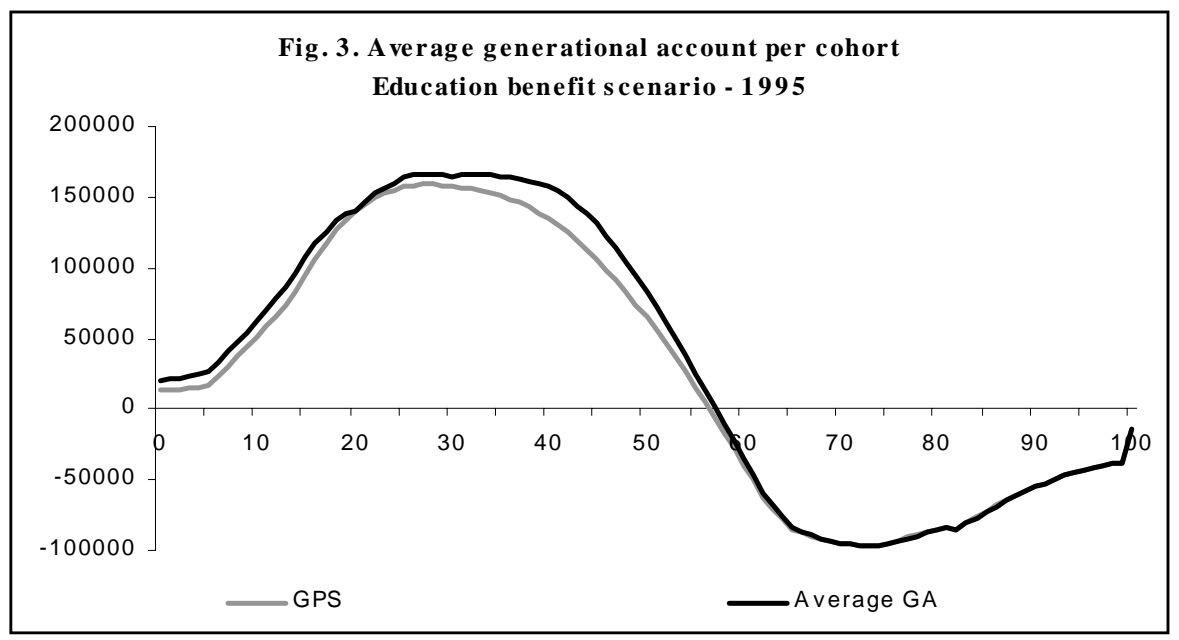

In this scenario, the total burden left on future generations amounts to $\$ 2,063$ billions (instead of $\$ 4,881$ in the GPS methodology). The current fiscal policy is still unsustainable and generates a budgetary long run deficit. The deficit is higher than in the baseline case. Education spending are increasing more quickly than in the baseline scenario due to the changes in the educational structure of the population. 
As depicted in table 5, restoring the balance through tax adjustment induces a rise in all taxes by about 1.39 percent (against 5.0 percent in GPS framework). The lifetime net tax rates then become -67.5 percent, 3.2 percent and 13.8 percent. Restoring the balance through transfer adjustment induces a cut in all transfers by about 2.38 percent (against 13.0 percent in GPS framework). The lifetime net tax rates become -65.3 percent, 3.5 percent and 13.9 percent.

Table 5. Generational imbalance and lifetime net tax rates Education benefit scenario (a)

\begin{tabular}{c|cccc}
\hline & $\begin{array}{c}\text { Present value of } \\
\text { taxes }\end{array}$ & $\begin{array}{c}\text { Present value of } \\
\text { benefits }\end{array}$ & $\begin{array}{c}\text { Generational } \\
\text { accounts }\end{array}$ & $\begin{array}{c}\text { Lifetime Net Tax } \\
\text { Rate (b) }\end{array}$ \\
\hline & Newborns' generational account and lifetime tax rate without policy adjustment \\
\hline$<$ HS & 45552 & -101081 & -55529 & $-68.2 \%$ \\
HS & 77682 & -73246 & 4436 & $2.5 \%$ \\
$>$ HS & 121860 & -80451 & 41409 & $13.3 \%$ \\
\hline & Restoring the balance through tax adjustment $(+1.39 \%)$ & \\
\hline$<$ HS & 46187 & -101081 & -54894 & $-67.5 \%$ \\
HS & 78766 & -73246 & 5519 & $3.2 \%$ \\
$>$ HS & 123560 & -80451 & 43109 & $13.8 \%$ \\
\hline & Restoring the balance through transfer adjustment $(-2.38 \%)$ & $-65.3 \%$ \\
\hline HS & 45552 & -98674 & -53122 & $3.5 \%$ \\
HS & 77682 & -71502 & 6180 & $13.9 \%$ \\
\hline HS & 121860 & -78535 & 43326 & \\
\hline
\end{tabular}

Note:

(a) Present value in 1995 dollars

Source:

(b) Lifetime net tax rate = generational account / discounted lifetime labor income Authors' calculations

\section{Sensitivity analysis}

Generational accounts depend on uncertain assumptions about demographic changes, labor productivity growth rate, budgetary policy, interest rate and the future trends of educational attainment. In this section, we analyze the sensitivity of our calculations to alternative assumptions about growth and interest rates and about the educational 
attainment of future cohorts.

As in GPS, our baseline scenario assumes a 6 percent discount rate and that productivity increases by 1.2 percent a year. This discount rate is roughly equal to the historical real rate of return on equity. A 1.2 percent productivity growth rate is a reasonable value given the past trend of labor productivity. Table 6 reports alternative projections when the interest rate amounts to 3 percent (a value closer to the real return on government bonds) or 9 percent (a value closer to the return on private capital) and when the labor productivity growth rate varies between 0.7 percent and 1.7 percent a year. These alternative scenarios are the same as those used in GPS analysis. The results must be compared to the baseline scenario in which education spending are included in government purchases.

Obviously, alternative assumptions about the rate of productivity growth have a minor effect on the results. Remember that the pure indexation of individual taxes and benefits on productivity growth is implemented after the year 2070. Before that date, the evolution of taxes and benefits relies on the $\mathrm{CBO}$ forecasts and is not much affected by the growth hypothesis. On the contrary, alternative assumptions about the interest rate modify the calculations. The lifetime net tax rate of low skill individuals is particularly affected when the interest rate changes. However, interest rates and growth rates do not modify the main result: in all cases, the current fiscal policy is unsustainable. The policy adjustments to restore the generational balance are robust (especially when the interest rate increases). The tax variation ranges from 
1.0 to 4.7 percent in the two extreme scenarios. Transfer cuts range from 2.5 to 9.0

percent.

Table 6. Generational accounts and budgetary adjustments Sensitivity to discount and growth rate assumptions

\begin{tabular}{|c|c|c|c|c|c|c|}
\hline & \multicolumn{6}{|c|}{ Newborns' generational account and lifetime tax rate without policy adjustment } \\
\hline & \multicolumn{3}{|c|}{ Generational accounts } & \multicolumn{3}{|c|}{ Lifetime net tax rate } \\
\hline$<\mathrm{HS}$ & $g=0.007$ & $g=0.012$ & $g=0.017$ & $g=0.007$ & $g=0.012$ & $g=0.017$ \\
\hline$i=0.03$ & -88290 & -89701 & -91204 & $-34.4 \%$ & $-35.0 \%$ & $-35.5 \%$ \\
\hline$i=0.06$ & -12391 & -12511 & -12638 & $-15.2 \%$ & $-15.4 \%$ & $-15.5 \%$ \\
\hline$i=0.09$ & -1124 & -1136 & -1148 & $-3.8 \%$ & $-3.8 \%$ & $-3.9 \%$ \\
\hline $\mathrm{HS}$ & $g=0.007$ & $g=0.012$ & $g=0.017$ & $g=0.007$ & $g=0.012$ & $g=0.017$ \\
\hline$i=0.03$ & 88015 & 86535 & 84943 & $17.3 \%$ & $17.0 \%$ & $16.7 \%$ \\
\hline$i=0.06$ & 46840 & 46708 & 46565 & $26.9 \%$ & $26.8 \%$ & $26.7 \%$ \\
\hline$i=0.09$ & 22485 & 22470 & 22453 & $33.0 \%$ & $33.0 \%$ & $33.0 \%$ \\
\hline$>\mathrm{HS}$ & $g=0.007$ & $g=0.012$ & $g=0.017$ & $g=0.007$ & $g=0.012$ & $g=0.017$ \\
\hline$i=0.03$ & 278223 & 276415 & 274400 & $27.8 \%$ & $27.7 \%$ & $27.5 \%$ \\
\hline$i=0.06$ & 100677 & 100487 & 100270 & $32.3 \%$ & $32.3 \%$ & $32.2 \%$ \\
\hline \multirow[t]{4}{*}{$i=0.09$} & 40481 & 40453 & 40419 & $35.8 \%$ & $35.8 \%$ & $35.8 \%$ \\
\hline & \multicolumn{6}{|c|}{ Restoring the generational balance through... } \\
\hline & \multicolumn{3}{|c|}{ Tax change (in $\%$ of the current policy) } & \multicolumn{3}{|c|}{ Transfer change (in $\%$ of the current policy) } \\
\hline & $g=0.007$ & $g=0.012$ & $g=0.017$ & $g=0.007$ & $g=0.012$ & $g=0.017$ \\
\hline$i=0.03$ & $3.5 \%$ & $4.0 \%$ & $4.7 \%$ & $-7.0 \%$ & $-7.8 \%$ & $-9.0 \%$ \\
\hline$i=0.06$ & $1.1 \%$ & $1.2 \%$ & $1.2 \%$ & $-2.5 \%$ & $-2.7 \%$ & $-2.9 \%$ \\
\hline$i=0.09$ & $1.0 \%$ & $1.1 \%$ & $1.1 \%$ & $-2.6 \%$ & $-2.7 \%$ & $-2.8 \%$ \\
\hline
\end{tabular}

Source: Authors' calculations

Finally, let us examine the sensitivity of our results to the assumptions about educational attainment of young and future generations. Our baseline scenario is based on Lee and Miller (1997). For the population aged 0 to 19 (those reaching age 20 between 1996 and 2015), Lee and Miller (1997) forecast educational attainment on the basis of parents' level of education and ethnicity. After 2015, we assume that the skill structure of future cohorts (aged 20 after 2015) is stationary. Regarding individuals who just completed schooling, the proportions of low, medium and high skilled workers in 1995 are respectively 13, 35 and 52 percent. In 2005, Lee and Miller forecast a slight decrease in educational attainment until 2005 (the proportions become 16, 32 and 52 percent). Then the shares converge towards 10.9, 28.9 and 60.2 
percent. These long-run proportion are reached in 2015. Compared to the study of Cheeseman Day and Bauman (2000), the baseline scenario must be considered as a reasonable medium variant.

Two alternative forecasts can be simulated. Building on the "high projection" of Cheeseman Day and Bauman (2000), the high variant is based on very optimistic assumptions about future educational attainment. In the long-run, it assumes that the proportions of high skilled workers aged 30 will reach 70.2 percent in 2030 (against 5.2 percent for low skilled workers and 24.6 for the medium skilled). Our "low variant" relies on the most pessimistic annual forecast from Lee and Miller. We keep the 2005 educational structure (16 percent for the low skilled, 32 and 52 percent for the medium and high skilled) as constant after that year.

Table 7 gives the results. Clearly, newborns' generational accounts and lifetime net tax rates are quite stable. In terms of generational balance, the low variant has a deep impact on the long run deficit. Taxes must be increased by 5.69 percent (instead of 1.16 in the baseline scenario) or transfers must be reduced by 12.52 percent (instead of 2.68 in the baseline). Alternatively, the optimistic variant built on Cheeseman Day and Bauman generates a long run budgetary surplus. A continued rise in educational attainment would make the fiscal policy sustainable: taxes could be reduced by 1.3 percent or transfers could be increased by 3.13 percent. Of course, reaching the high variant's educational attainment would probably require a strong expansionary education policy. If the marginal cost of education is increasing, the 
discounted cost of such a policy could exceed the discounted fiscal gains. In some sense, the baseline scenario seems more realistic since it relies on the current State intervention. Nevertheless, our sensitivity analysis demonstrates the crucial role of education policies in the debate on aging and public finance.

Table 7. Generational accounts and budgetary adjustments Sensitivity to the long-run educational structure

\begin{tabular}{|c|c|c|c|c|c|c|}
\hline & \multicolumn{6}{|c|}{ Newborns' generational account and lifetime tax rate without policy adjustment } \\
\hline & \multicolumn{3}{|c|}{ Generational accounts } & \multicolumn{3}{|c|}{ Lifetime net tax rate } \\
\hline & Low & Baseline & High & Low & Baseline & High \\
\hline$<\mathrm{HS}$ & -12261 & -12511 & -13820 & $-15.1 \%$ & $-15.4 \%$ & $-17.0 \%$ \\
\hline HS & 46940 & 46708 & 45728 & $26.9 \%$ & $26.8 \%$ & $26.2 \%$ \\
\hline \multirow[t]{8}{*}{$>\mathrm{HS}$} & 100653 & 100487 & 99651 & $32.3 \%$ & $32.3 \%$ & $32.0 \%$ \\
\hline & \multicolumn{6}{|c|}{ Restoring the generational balance through... } \\
\hline & \multicolumn{3}{|c|}{ Tax change (in $\%$ of the current policy) } & \multicolumn{3}{|c|}{ Transfer change (in $\%$ of the current policy) } \\
\hline & Low & Baseline & High & Low & Baseline & High \\
\hline & $5.69 \%$ & $1.16 \%$ & $-1.30 \%$ & $-12.52 \%$ & $-2.68 \%$ & $3.13 \%$ \\
\hline & \multicolumn{6}{|c|}{ Newborns' lifetime tax rate after policy adjustment through... } \\
\hline & \multicolumn{3}{|l|}{ Tax change } & \multicolumn{3}{|c|}{ Transfer change } \\
\hline & Low & Baseline & High & Low & Baseline & High \\
\hline$<\mathrm{HS}$ & $-11.9 \%$ & $-14.7 \%$ & $-17.7 \%$ & $-6.2 \%$ & $-13.5 \%$ & $-19.3 \%$ \\
\hline HS & $29.5 \%$ & $27.3 \%$ & $25.7 \%$ & $29.1 \%$ & $27.3 \%$ & $25.7 \%$ \\
\hline$>\mathrm{HS}$ & $34.5 \%$ & $32.7 \%$ & $31.5 \%$ & $33.2 \%$ & $32.4 \%$ & $31.8 \%$ \\
\hline
\end{tabular}

Source: Authors' calculations

\section{Conclusion}

It is usually argued that expected demographic changes threaten the sustainability of fiscal policies. In most industrialized countries, social policies involve considerable transfers from young cohorts to old cohorts. If the number of beneficiaries increases, the financial viability of the system is obviously questioned. Generational accounting is perceived as a meaningful way to evaluate the sustainability of fiscal policy. Updated calculations made for the US reveal a large generational imbalance which can be restored by increasing taxes or cutting transfers. 
To the best of our knowledge, these studies do not take account of a remarkable change in the characteristics of people, the rise in educational attainment. This change is budgetary important since it strongly modifies the fiscal means and needs of successive generations. In this paper, we disaggregate tax and benefit age-profiles per schooling level. This reveals strong differences in net taxes among living generations. Aggregating these net taxes on a whole lifetime basis, we show that the low skill newborns' account is negative (-15.4 percent of their lifetime labor income) whilst medium and high skill newborns have positive accounts (26.8 percent and 32.3 percent of their lifetime labor income). Taking account of the (past and expected) changes in the educational structure avoids two sources of bias: the overestimation of the total burden left on future generations and the underestimation of the fiscal capacity of these future generations.

Our results are more optimistic than those of existing studies. Our baseline scenario indicates that the current fiscal policy (defined by the current level of taxes and transfers as well as by the growth assumptions of per capita taxes and benefits provided by the CBO) generates a long-run deficit. However, the deficit is much lower than the GPS predictions. Restoring the generational balance requires cutting transfers by 2.7 percent or increasing taxes taxes by 1.2 percent. These results are quite robust to our assumptions about labor productivity growth, interest rate. Treating education expenditures as transfers gives similar results. However, results are sensitive to assumptions about the educational structure of future cohorts. 
Is that a sufficient reason to move from a highly pessimistic position to a highly optimistic one? This strongly depends on the (at least relative) stability of net tax profiles per schooling level. We should keep in mind that generational accounting is a pure mechanical projection tool which keeps these relative differences as constant over time. It does not take account of the interdependencies between the demography, the changes in the educational structure and the economy. If young generations are more and more educated, the average cost of education per student could be affected. If unskilled and skilled labor are imperfect substitutes on the labor market, an increase in the supply of skills could give rise to a drop in the skill premium and a possible rise in fiscal needs of the highly skilled. We could then observe a shift of skilled agents' net taxes closer to unskilled agents' ones. It is worth noticing that it did not happen in the past. In spite of a huge rise in educational attainment, returns to skills have also increased substantially over the last four decades. Moreover, recent theories of endogenous technical biases suggest that a positive relationship between the skill premium and the average level of schooling is likely to emerge in the long-run. As argued by Acemoglu (2002), a rise in the education level of the labor force stimulates investments in skill-consuming technical processes and increases the long run demand for skilled workers. Compared to our predictions, this would reinforce the role of education on public finance. It is however difficult to forecast the evolution of the skill premium without a long-run model of the US economy. Integrating generational accounts and fiscal policies in such a framework is obviously a promising issue that 
we leave for further research.

\section{References}

- Acemoglu, D., 2002, "Technical change, inequality and the labor market", Journal of Economic Literature XL, 7-72.

- Auerbach, A.J., J. Gokhale and L.J. Kotlikoff, 1991, "Generational accounts: a meaningful alternative to deficit accounting", in Bradford, D. (ed.), Tax policy and the economy, vol. 5, 55-110, Cambridge: MIT Press.

- Auerbach, A.J., J. Gokhale and L.J. Kotlikoff, 1994, "Generational accounts: a meaningful way to evaluate fiscal policy", Journal of Economic Perspectives 8(1), 73-94.

- Auerbach, A.J. and P. Oreopoulos, 1999, "Analyzing the fiscal impact of US immigration", American Economic Review 89, 176-180.

- Bonin, H., B. Raffelhüschen and J. Walliser, 2000, "Can immigration alleviate the demographic burden", FinanzArchiv 57(1).

- Cheeseman Day, J. and K.J. Bauman, 2000, "Have we reach the top? Educational attainment projections of the US population", Population Division Working Paper, 43, US Census Bureau. 
- Collado, M.D., I. Iturbe-Ormaetxe and G. Valera, 2001, "Quantifying the impact of immigration in the Spanish welfare state", paper presented at the EEA annual meeting, Lausanne.

- Congressional Budget Office, 1997a, An economic model for long-run budget simulations, CBO, July.

- Congressional Budget Office, 1997b, The economic and budget outlook: an update, US Government Printing Office, September.

- Gokhale, J., B.R. Page and J.R. Sturrock, 1999, "Generational accounts for the United States: an update", in Auerbach, A.J., L. J. Kotlikoff and W. Leibfritz (ed.), Generational Accounting Around the World, NBER Books, The University of Chicago Press.

- Haveman, R., 1994, "Should generational accounts replace public budgets and deficits?", Journal of Economic Perspectives 8(1), 95-111.

- Kotlikoff, L.G., 1992, Generational accounting: knowing who pays, and when, for what we spend, New York: The Free Press.

- Lee, R.D. and T. Miller, 1997, "Immigrants and their descendants", Project on the economic demography of interage income reallocation, Demography, UC Berkeley. 


\section{Appendix}

\subsection{Methodology with heterogenous agents}

The starting point of the generational accounting technique is the government's intertemporal budget constraint. At the base year $t$, the sum of the public net wealth and the present value of prospective aggregate net payments by living and future generations must equalize the present value of prospective public purchases:

$$
P V L_{t}+P V F_{t}+N W_{t}=P V G_{t}
$$

where $P V L_{t}$ measures the present value of net tax payments by living generations over the rest of their life, $P V F_{t}$ is the present value of net tax payments by future generations, $P V G_{t}$ stands for the present value of prospective government purchases of goods and services and $N W_{t}$ is the net public wealth.

The net wealth at time $t$ is observed. Two of the remaining terms are projected using contemporaneous observations and official projections, $P V G_{t}$ and $P V L_{t}$. The fourth term, $P V F_{t}$, can thus be calculated as the residual burden bequeathed to future generations.

The present value of government purchases is the discounted sum of public expenditures:

$$
P V G_{t}=\sum_{s=t}^{\infty} \frac{G_{s}}{(1+i)^{s-t}}
$$


where $G_{s}$ is the amount of public purchases projected at time $s \geq t ; i$ denotes the interest rate. In practice, the path of $G_{s}$ can be partly projected on the basis of budgetary forecasts (i.e. between $t$ and $t^{*}$ ) and partly projected using balanced growth assumptions (between $t^{*}$ and $\infty$ ). In the long-run, it is assumed that $G_{s}$ grows at the same rate as the growth rate of the total factor productivity, $g$.

The present value of net tax payments by living generations can be obtained by summing the present value of net taxes these generations will pay to the government over the rest of their life, i.e. summing the generational accounts of living cohorts. We distinguish three educational levels $(L=$ low level, $M=$ mean level and $H=$ high level) and suppose that each individual can live a maximum of $D$ years. The present value of payments by living generations, $P V L_{t}$, can be written as

$$
P V L_{t}=\sum_{j=0}^{D}\left(n_{j, t}^{L} p_{j, t}^{L}+n_{j, t}^{M} p_{j, t}^{M}+n_{j, t}^{H} p_{j, t}^{H}\right)
$$

where $p_{j, t}^{X}$ stands for the size of type- $X$ population $(X=L, M, H)$ of age $j$ at time $t$, $n_{j, t}^{X}$ measure the generational account of these agents.

Generational accounts sum up the amount of net tax to be paid by each type of individual over the rest of his life:

$$
n_{j, t}^{X}=\frac{1}{p_{j, t}^{X}} \sum_{k=j}^{D} \frac{\theta_{k, t+k-j}^{X} p_{k, t+k-j}^{X}}{(1+i)^{k-j}} \quad j=0, \ldots, D
$$

where $\theta_{k, t+k-j}^{X}$ is the amount of net tax payment by an agent of type $X$ and age $k$ at 
time $t+k-j$.

In practice, $p_{k, t+k-j}^{X}$ can be projected using demographic forecasts (including mortality and net immigration flows), data on schooling levels per age, and estimates for the educational attainment of the young living generations after completion of their education. The net taxes $\theta_{k, t+k-j}^{X}$ can be partly extrapolated on the basis of short-run forecasts (taking account of official budgetary projections and potential fiscal reforms between $t$ and $t^{*}$ ) and partly extrapolated using balanced growth assumptions (between $t^{*}$ and $\left.\infty\right)$. Typically, different assumptions can be considered for the items of $\theta_{k, t+k-j}^{X}$

It should be noted that the generational accounts of the newborns, measuring the present value of net taxes they expect to pay over their whole lifetime, need not to be of the same sign. It can be negative for low skill individuals and positive for the high skilled. These generational accounts can be expressed as percentage of the discounted lifetime labor income, denoted by $W_{0, t}^{X}$ for a newborn agent of type $X$. In the line of GPS, this defines the lifetime net tax rate of the newborns:

$$
L N R_{0, t}^{X}=\frac{n_{0, t}^{X}}{W_{0, t}^{X}}
$$

The basic issue of the generational accounting is the financial sustainability of public policies. Given the generational account of the newborns at time $\mathrm{t}\left(n_{0, t}^{X}\right)$, will it be possible to be so generous with future generations? The present value of net tax payment by future generations, $P V F_{t}$, does not itself give an answer to 
this question. To go further, one needs to transform this aggregate burden into an individual amount, the average account of future cohorts.

One way to proceed is to compute the hypothetical generational accounts of future cohorts under the current fiscal policy. Using the same methodology than in (3) and (4), we write:

$$
P V F_{t}^{*}=\sum_{s=t+1}^{\infty} \sum_{j=0}^{\operatorname{Min}[s-t-1 ; D]} \frac{\theta_{j, s}^{L} p_{j, s}^{L}+\theta_{j, s+j}^{M} p_{j, s}^{M}+\theta_{j, s+j}^{H} p_{j, s}^{H}}{(1+i)^{s-t}}
$$

where $P V F_{t}^{*}$ measures the present value of net payments by future generations under the assumption that the current fiscal policy is sustainable.

This hypothetical value can then be compared to the residual value $P V F_{t}$ computed from (1):

- if $P V F_{t}^{*}=P V F_{t}$, the policy is sustainable and there is no need of fiscal adjustment;

- if $P V F_{t}^{*}>P V F_{t}$, the government budget is in surplus so benefits could be increased for the same levels of taxes;

- if $P V F_{t}^{*}<P V F_{t}$, the current policy is not sustainable or not generationally balanced: it implies that either future generations must pay different net taxes than current generations or current policy must be adjusted to restore sustainability.

In case of unsustainability, the basic methodology suggest to adjust taxes and/or 
transfers at some date. In this paper, we use an adjustment method which concerns all the members of all the generations. If a gap has to be financed (in case of deficit) or allocated (in case of surplus), we compute the proportional adjustment in all taxes (or in all transfers) required to balance the budget ${ }^{7}$.

Let us decompose the net taxes on all generations in two basic components, taxes and benefits: $\theta_{j, s}^{X}=\theta_{T, j, s}^{X}-\theta_{B, j, s}^{X}$. A time-invariant adjustment factor can be applied to each of these components $\left(\eta_{T}\right.$ for taxes and $\eta_{B}$ for benefits) so as to restore sustainability. We then apply these proportional changes to both living generations (over the rest of their lifetime) and future generations so as to balance the budget constraint. Our adjustment rule is then summarized by the following set of equations:

$$
\begin{aligned}
P V L_{t}^{a d j} & =\sum_{j=0}^{D} \sum_{k=j}^{D} \sum_{X=L, M, H} \frac{\left[\theta_{T, k, t+k-j}^{X}\left(1+\eta_{T}\right)-\theta_{B, k, t+k-j}^{X}\left(1-\eta_{B}\right)\right] p_{k, t+k-j}^{X}}{(1+i)^{k-j}} \\
P V F_{t}^{a d j} & =\sum_{s=t+1}^{\infty} \sum_{j=0}^{M i n[s-t-1 ; D]} \sum_{X=L, M, H} \frac{\left[\theta_{T, j, s}^{X}\left(1+\eta_{T}\right)-\theta_{B, j, s}^{X}\left(1-\eta_{B}\right)\right] p_{j, s}^{X}}{(1+i)^{s-t}} \\
P V G_{t} & =P V L_{t}^{a d j}+P V F_{t}^{a d j}+N W_{t}
\end{aligned}
$$

There is a continuum of pairs $\left(\eta_{T}, \eta_{B}\right)$ restoring the balance. Two specific pairs are usually considered, one with $\eta_{T}=0$ if the balance is achieved through transfer cuts and one with $\eta_{B}=0$ if the balance is achieved through tax increases. For each scenario, the lifetime tax rate of future generations can be computed and compared to that of the current newborns.

\footnotetext{
${ }^{7}$ It should be noted that, in the line of GPS, the balance can also be restored through changes in government purchases
} 


\subsection{An alternative scenario: trusting CBO projections}

The CBO projection does not take account of the rise in educational level of the pop-

ulation. Let us examine an alternative scenario where the growth rates of per capita taxes and transfers are calibrated so as to match the CBO aggregated projections (for each item). In that case, the average generational accounts of living generations are almost identical to those reported in GPS study. Nevertheless, our methodology allows to disaggregate living generations' account by schooling level. In table A1, it is shown that the lifetime net tax rate amounts to -26.0 percent for the low skilled, 22.7 percent for the medium skilled and 28.7 percent for the high skilled. Applying CBO projections up to 2070 also determines the prospective contribution of future generations. It is only after 2070 that the our calculations become highly sensitive to the educational structure of the population. Our generational balanced policy is thus very close to that suggested in GPS study. Restoring the balance requires increasing all taxes by 8.16 percent or reducing all transfers by 17.54 percent (this is not significantly different from GPS).

Is this scenario based on $\mathrm{CBO}$ aggregated projections more consistent than our baseline scenario? Our answer depends on the growth rates of per capita taxes and benefits. Table A.2 compares the average growth rates per item for the period 20102050. Our calculations indicate that the baseline growth rates are more consistent with the 1.2 percent growth rate of labor productivity. This is especially the case for individual taxes. In our baseline scenario, the growth rate of labor income tax, capital 
income tax and FICA are fully consistent with the growth rate of labor productivity.

In the other scenario, this is obviously not the case. The gap between labor produc-

tivity growth and the growth rates of per capita benefit is also smaller in our baseline

scenario.

Table A1. Generational imbalance and lifetime net tax rates

Baseline scenario (a)

\begin{tabular}{c|cccc}
\hline & $\begin{array}{c}\text { Present value of } \\
\text { taxes }\end{array}$ & $\begin{array}{c}\text { Present value of } \\
\text { benefits }\end{array}$ & $\begin{array}{c}\text { Generational } \\
\text { accounts }\end{array}$ & $\begin{array}{c}\text { Lifetime Net Tax } \\
\text { Rate (b) }\end{array}$ \\
\hline & Newborns' generational account and lifetime tax rate without policy adjustment \\
\hline$<$ HS & 42699 & -63826 & -21127 & $-26.0 \%$ \\
HS & 72377 & -32804 & 39573 & $22.7 \%$ \\
$>$ HS & 111295 & -21888 & 89406 & $28.7 \%$ \\
\hline & Restoring the balance through tax adjustment & $+8.16 \%)$ & \\
\hline$<$ HS & 46182 & -63826 & -17644 & $-21.7 \%$ \\
HS & 78281 & -32804 & 45477 & $26.1 \%$ \\
$>$ HS & 120373 & -21888 & 98484 & $31.6 \%$ \\
\hline & \multicolumn{4}{|l}{ Restoring the balance through transfer adjustment $(-17.54 \%)$} \\
\hline$<$ HS & 42699 & -52631 & -9932 & $-12.2 \%$ \\
HS & 72377 & -27050 & 45327 & $26.0 \%$ \\
$>$ HS & 111295 & -18049 & 93246 & $29.9 \%$ \\
\hline
\end{tabular}

Note: $\quad$ (a) Present value in 1995 dollars

(b) Lifetime net tax rate = generational account $/$ discounted lifetime labor income

Source: Authors' calculations

Table A2. Average yearly growth rate of per capita taxes and benefits (2010-2050)

"Baseline scenario" vs "Trusting CBO"

\begin{tabular}{lccccccc}
\hline Benefits & OASDI & Medicare & Medicaid & UI & Gen. Welfare & AFDC & Food Stamps \\
\hline Trusting CBO & $0.4 \%$ & $1.6 \%$ & $2.3 \%$ & $1.2 \%$ & $1.7 \%$ & $1.7 \%$ & $1.7 \%$ \\
Baseline scenario & $0.6 \%$ & $1.5 \%$ & $1.9 \%$ & $1.1 \%$ & $0.9 \%$ & $1.2 \%$ & $1.1 \%$ \\
\hline Taxes & Labor Inc. & FICA & Excise & Capital Inc. & Property & & \\
\hline Trusting CBO & $0.9 \%$ & $0.9 \%$ & $0.7 \%$ & $0.1 \%$ & $0.5 \%$ & \\
Baseline scenario & $1.2 \%$ & $1.1 \%$ & $1.0 \%$ & $0.9 \%$ & $0.8 \%$ & \\
\hline Source: & GPS (1999) and authors' calculations & & &
\end{tabular}

